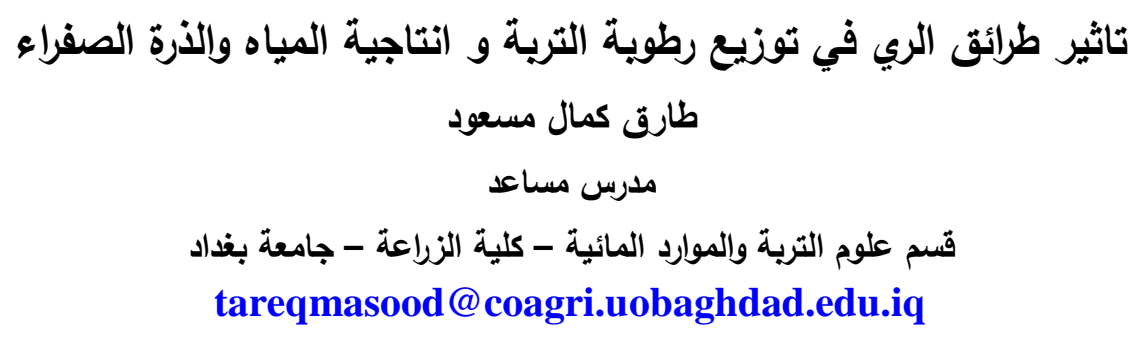

المستخلص

اجريت تجربة حقلية للموسم الربيعي 2015 في ناحية الرشيد جنوب بغداد لاراسة التوزيع الرطوبي عند تطبيق طرائق ري المروز الضحلة

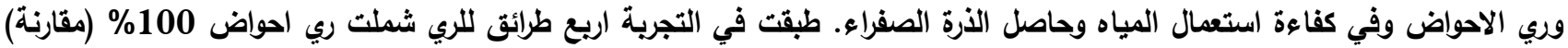

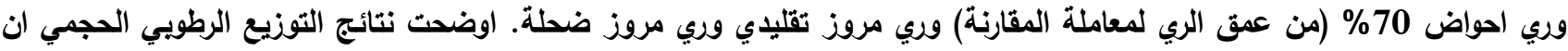

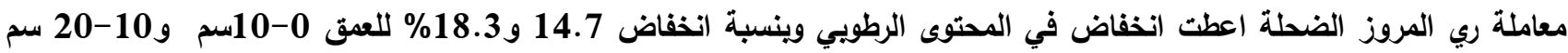
على الترتيب قياساً بمعاملة ري الاحواض التقليدي وفي الوقت ذاته اختلفت بقية المعاملات في التوزيع الرطويي عن معاملة القياس ـ بينت

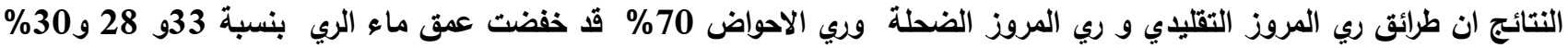

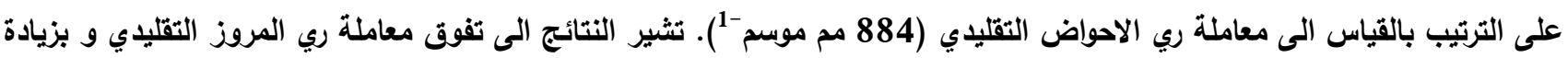

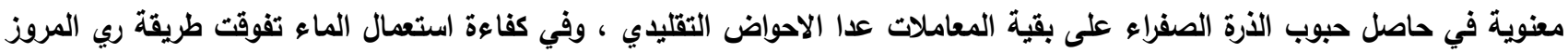

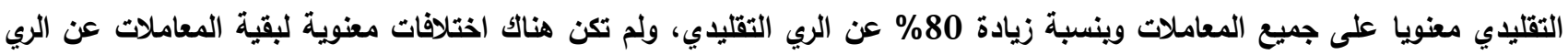
التقليدي. وبهذا يكون الري عند تطبيق الري الاحواض 70\% والمروز الضحلة اكثر ربحية مقارنة بتحقيق حاصل اعلى عذد استعمال الري

\title{
EFFECT OF IRRIGATION METHODS ON WATER CONTENT DISTRIBUTION, WATER AND CORN PRODUCTIVITY
}

\author{
T. K. Masood \\ Assist. Lecturer \\ Department of Soil Science and Water Resources - College of Agriculture - University of Baghdad \\ tareqmasood@coagri.uobaghdad.edu.iq
}

ABSTRACT

Field experiment was carried out during spring seasons of 2015 in AL-Rasheed township southern of Baghdad, Iraq to study the effects of irrigation methods on water content distribution, water use efficiency and yield of corn. Four surface irrigation treatments were used: $100 \%$ conventional basin (control), $70 \%$ of control treatment basin irrigation, Conventional furrow and shallow furrow. Water content distribution results showed that shallow furrow irrigation decreased moisture content to $14.7,18.3 \%$ for $0-10$ and $10-20 \mathrm{~cm}$ depth respectively, compared to conventional basin irrigation. The result showed that treatments of conventional furrow, shallow furrow and $\mathbf{7 0 \%}$ basin irrigation reduced the depth of added water in rate of 33, 28 and $30 \%$, respectively comperd to control treatment $\left(884 \mathrm{~mm} \operatorname{season}^{-1}\right)$. Conventional furrow irrigation significantly increased corn grain yield to all treatments except conventional basin. In the mean while, other treatment did not differ from the conventional irrigation method. Water use efficiency of conventional furrow irrigation was significantly higher than all other treatments with $80 \%$ increment than others. Thus the $70 \%$ basin irrigation and shallow furrow irrigation is more productive yield when compared with traditional irrigation.

Keywords: shallow furrow, water use efficiency, $70 \%$ basin irrigation 
الطريقة فعالة وناجعة في خفض الاحتياج المائي بنسبة 28\% المقدمة وزيادة في حاصل الحنطة تصل الى 22\% مقارنة بطريقة الري التقليدي. وعند دراسة التوزيع الملحي في المروز الضحلة ومقارنتها مع الري التقليدي انخفضت ملوحة التربة عند الطبقة

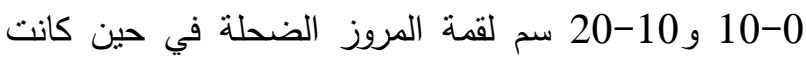
هناك زيادة عند القعر (3). ولما كانت نتائج المروز الضحلة جيدة في خفض الاحتياج المائي والدراسات محدودة في هذا

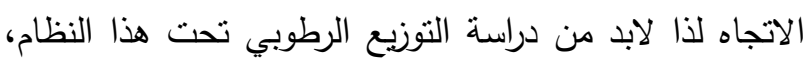

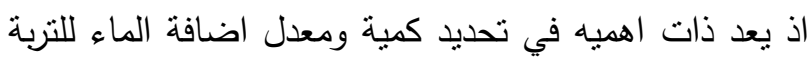
فضلاً عن برامج التشغيل والارواء. المواد والطرائق نفذت تجربة حقلية للموسم الربيعي 2015 في ناحية الرشيد جنوب بغداد، في تربة مزيجة غرينية مصنفة الى نيله

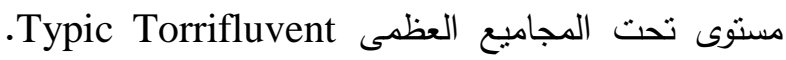
اخذت عينات من تربة الحقل قبل الزراعة، لغرض تحديد خصائصها ويبين جدول 1 الخصائص الفيزيائية و الكيميائية

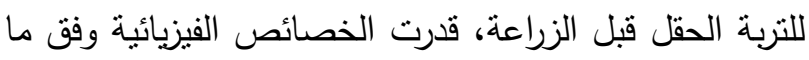
ورد في Black) والخصائص الكيميائية وفق ما جاء في Page وآخرون (15). جدول 1. الخصائص الكيميائية والفيزيائية لتربة الحقل قبل الزراعة

\begin{tabular}{|c|c|}
\hline 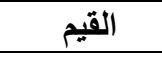 & الصفات \\
\hline 4.9 & EC \\
\hline 7.48 & pH \\
\hline 23.0 & النتروجين الجاهز(ملفم عنصر كفم-1 تربة) \\
\hline 15.0 & الفسفور الجاهز(ملفم عنصر كفم-1 تربة) \\
\hline 151 & البوتاسيوم الجاهز(ملغم عنصر كفم-1 تربة) \\
\hline 292 & الرمل (غرام كفم-1) \\
\hline 500 & الغرين(غرام كفم-1) \\
\hline 208 & الطين(غرام كفمَ1-1) \\
\hline Silt loam & نسجة التربة \\
\hline 0.390 & السعة الحقلية (د ) \\
\hline 0.123 & نقطة الذبول الدائم (سم³ سم-3) \\
\hline 0.267 & الماء الجاهز(سم3 \\
\hline 1.3 & الكثافة الظاهرية(ميكاغرام م-3) \\
\hline
\end{tabular}

حرثت نربة موقع التجربة حراثة متعامدة بوساطة المحراث

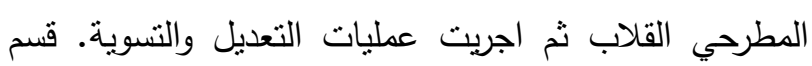
الحقل الى ثلاثة قطاعات رئيسة وقسمت القطاعات الى الى

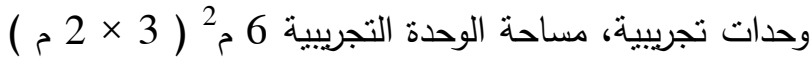
وفق تصميم القطاعات الكاملة المعثاة وبثلاثة مكررات. المروز التقليدية كانت المسافة بينها 0.75 م وبعرض 0.50

تعد المياه المورد الطبيعي الاكثر وفره على الكرة الارضية، لكن كمية قليلة منه بحدود 2.53\% هي مياه عذبة نستخدم

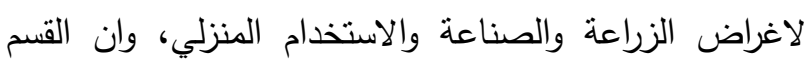
الاكبر من هذه المياه تكون محجوزه في الجليد او مياه جوفية،

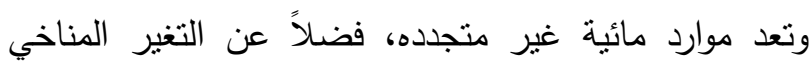
خطره في تسريع الجفاف والتصحر مما يؤدي الى ضئ ضياع

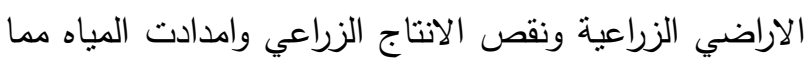

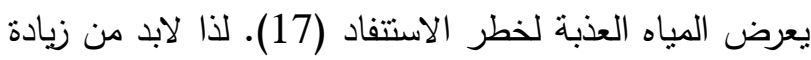
انتاجية المياه (كفاءة استعمال المياه) والتي عرفت على انها لانهاه كمية الانتاج لكل وحدة من المياه المضافة، مما يجعلها مناحة لاستخدامات أخرى (10). ومن الطرائق الرئيسة لتحسين إنتاجية المياه هو تطوير أصناف من المحاصيل الزراعية لا لانيل تتطلب كميات كبيرة من المباه ولاسيما في المناطق الجافة وشبه الجافة فضلا عن استخدام اسلوب الري بالمياه العذبة

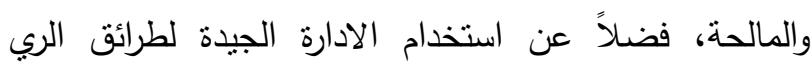

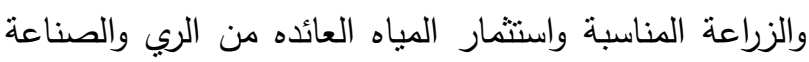
في زراعة مساحات اضافية(1 و6 و و14). لذا لابد من التفكير في احداث تغيرات في نمط الري ولاسيما انظمة الري غير

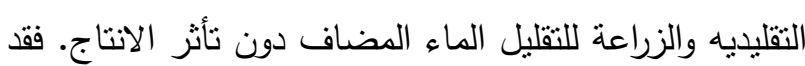

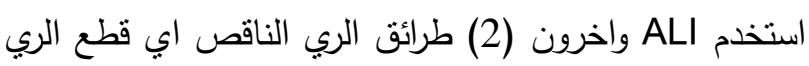
بعد كل ريتين متتاليتنين واستخدام الزراعة الكثيفة او المتداخلة (محصول بقولي مع محصول الذرة الصفراء) بكمية مياه الري نفسها لكلا المحصولين فضلاً عن الحد من التسميد الزائد

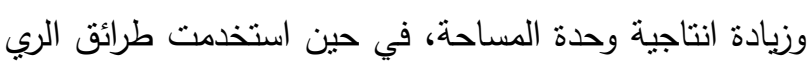

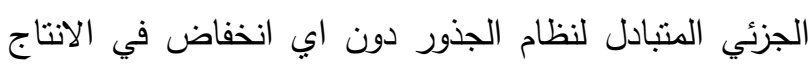
(8 و9 و 12 و13 و16). كما ان تغير نمط الزراعة لكي يتلائم مع التغيرات التي تطرأ على طريقة الري ضرورة ملحة

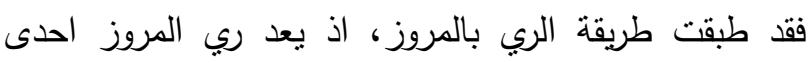

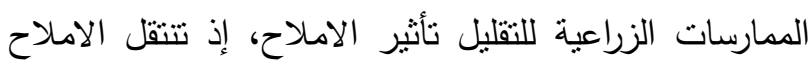

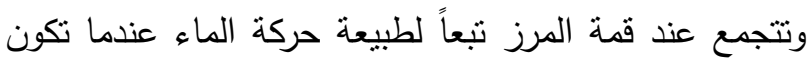
معدلات التبخر من سطح التربة عالية، وهذا يجعل الجذور النباتية بعيدة عن التأثنر المباشرة للاملاح ولاسيما المروز الضحلة (3 و 7 و 11). استخدم Masood (14) المروز الضحلة في الزراعة واكدت النتائج التي حصل عليها ان هذه 
قدرت المساحة الاضافية التي يمكن استثمارها بتطبيق المعادلة الاتية (14): (14)

مساحة الارض الاضافية التي يمكن استثمارها (هـ) =نسبة الماء الموفر

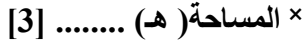

قدرت رطوبة التربة عند منتصف الموسم، بعد الري ب24

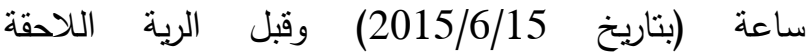

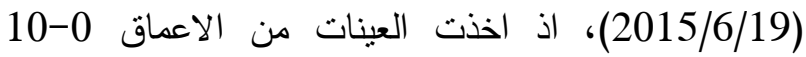
و 10-20 و 20-30 و 30-40 سم عموديا لجميع المعاملات وافقيا لمعاملات ري المروز التقليدي 0 و 15 و 30 سم (قمة ونة وجانب وقعر المرز التقليدي) و0 و15 سم (قمة وقعر)

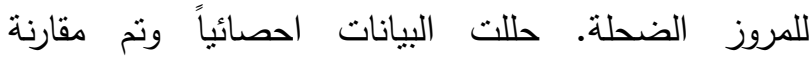
المتوسطات عند اختبار اقل فرق معنوي (LSD) عند مستوى ونم

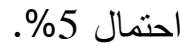

\section{النتائج والمناقشة}

يبين شكل1 التوزيع الرطوبي الحجمي في مقد التربة وللاعماق 0-40 سم من سطح التربة ولمعاملة ري الاحواض التقليدي. اذ يتضح ان اعلى محتوى رطوبي بعد الري بـ24 ساعة كان

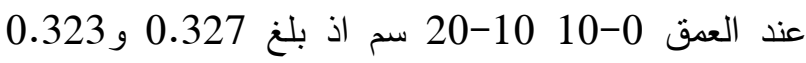
سم3 سم -3 على الترتيب. وانخفض المحتوى الرطوبي عند الطبقة تحت السطحية 20-30 و 30-40 سم، في حين اختلف التوزيع الرطوبي خلال مدة مابين الريتين (بعد 4 ايام)

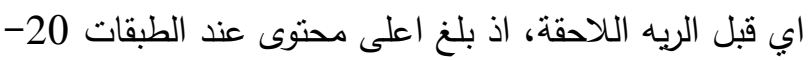

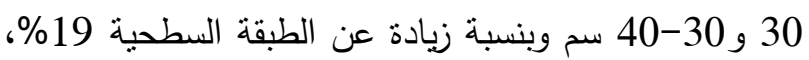
وهذا يعود الى زيادة التبخر من سطح التربة، فضلاً عن زيادة

الاستهلاك المائي.

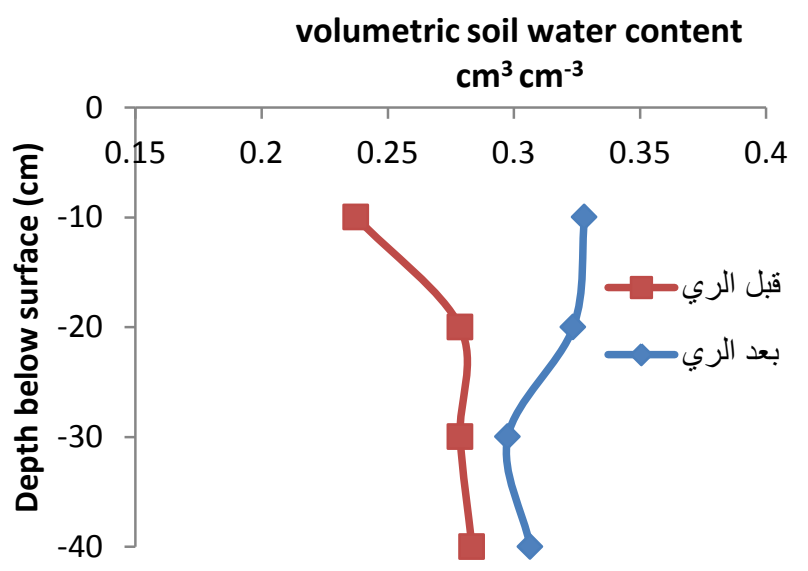

شكل 1. التوزيع الرطوبي لمقد التربة لمعاملة الري الاحواض التقليدي بعد الري وقبل الرية اللاحقة.
م وبعمق 0.20 م، والمروز الضحلة كانت المسافة بين مرز

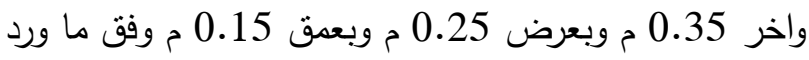
في (14). شملت التجربة طرائق الري الاتية : ري احواض

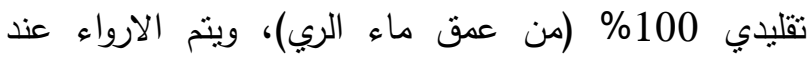

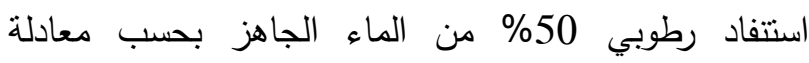
Allen $d=\left(\theta_{\text {f.c }}-\theta_{\mathrm{w}}\right) \mathrm{D}$....[1]

اذ ان d يمثل عمق ماء الري (مم) و ؤر الرطوبة الحجمية

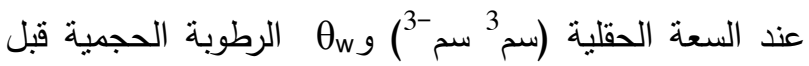

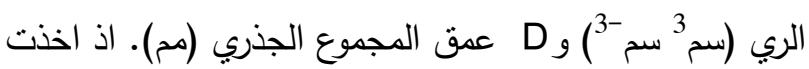
العينات لتقدير المحتوى الرطوبي قبل كل رية، وبحسب الطريقة الوزنية. وابعاد الاحواض هي 3×2 م مستوية السطح وبدون انحدار محاطة بكتوف ارتفاعها 0.30 م. و ري إي احواض 70\%: اضافة 70\% من عمق الماء المضاف لمعاملة الري التقليدي، و ري مروز تقليدي: عمق ماء الري ماهي لمعاملة ري الاحواض التقليدي × 0.67 (نسبة الاختزال بالمساحة)، و ري مروز ضحلة: اضافة عمق ماء الري نفسه لمعاملة الري التقليدي × ×0.72 0.72 (نسبة الاختزال بالمساحة).

وتحسب نسبة الاختزال بالمساحة من خلال العلاقة التالية:

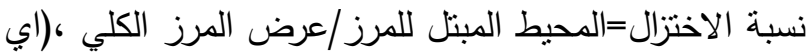
نسبة الاختزال للمروز=0.75/0.50 =0.67 ، وهكذا للمروز

الضحلة). زرعت بذور الذرة الصفراء صنف 5018 في الحقل بتاريخ 2015/4/18 على خطوط المسافة بين خط واخر 0.75 م وبين نبات واخر 0.25 م لمعاملتي اري الاحواض التقليدي 100\% و 70\%، وعلى جانب المرز للمسافة نفسها اعلاه لمعاملة ري المروز التقليدي، وفي قعر المرز للمسافات نفسها (اي بين مرز ضحل واخر) عند تطبيق المروز الضحلة. اضيفت الاسمدة النتروجينية بمعدل 200 كغم N هـ -1 على لئى دفعتين، واضيفت الاسمدة الفوسفاتية بمعدل 40 كغم Pهـ والاسمدة البوتاسية بمعدل 50 كغم K هـ-1 دفعة واحدة ـ قدر حاصل الحبوب الكلي من متوسط حاصل الوحدة التجربيية بعد بهد تفريط العرانيص ومن ثم التحويل الى كغم هـ -1. حسبت انتاجية المياه (كغم هـ -1 مم -1") من المعادلة الاتية: انتاجية المياه= حاصل الحبوب (كفم هـ-1)/عمق الماء المضاف (مم) [2] 
تحت قمة المرز بنفس المحتوى الرطوبي للعمق 30-40 سم

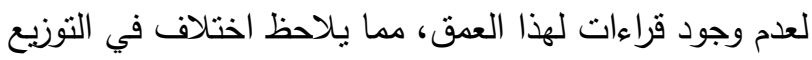
الرطوبي بالقياس الى اسفل قعر المرز • وبعد فترة زمنية معينة اي قبل الرية اللاحقة انخفض المحتوى الرطوبي عند سطح

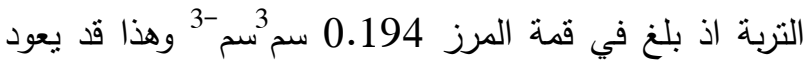

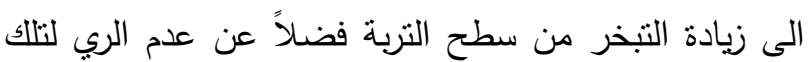
المنطقة. ويلاحظ هناك زيادة تدريجية في المحتوى الرطوبي لئي

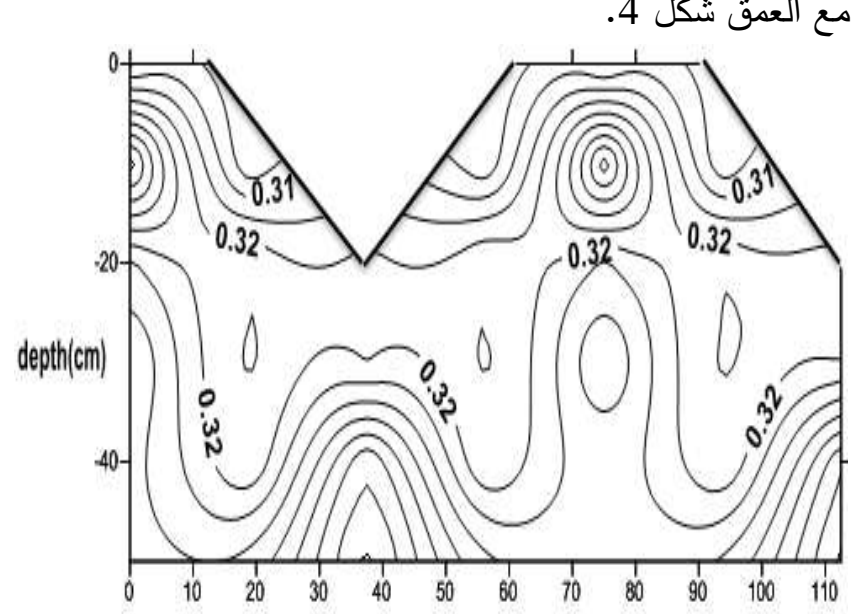

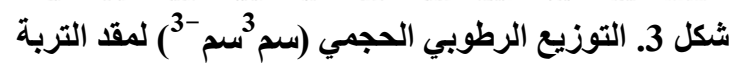
لمعاملة الري المروز التقليدي بعد الري مع العمقيم(سم)

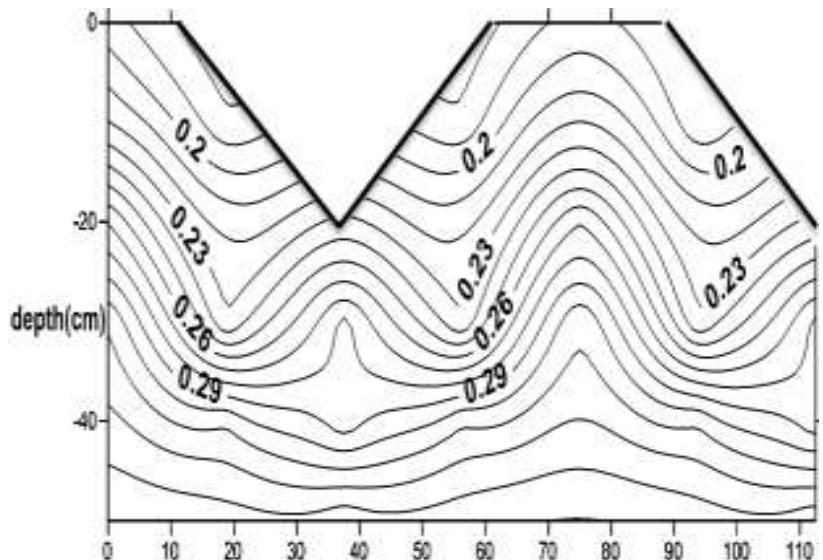

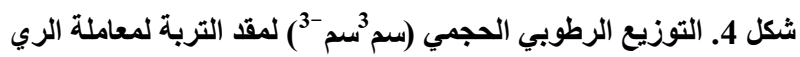
المروز التقليدي قبل الريه اللاحقة مع العمق(سم)

يبين شكل 5 التوزيع الرطوبي لمقد التربة ولمعاملة ري المروز المئل الضحلة اذ تراوح المحتوى الرطوبي بعد الريه ما بين 0.326

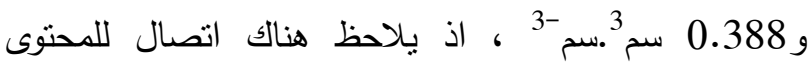
الرطوبي اسفل قمة وقعر المرز الضحل وقبل الرية اللاحقة اختلف التوزيع الرطوبي، اذ اوضحت النتائج ان هناك زيادة

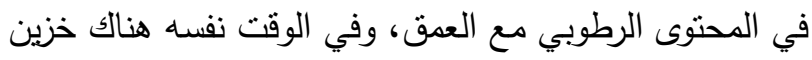

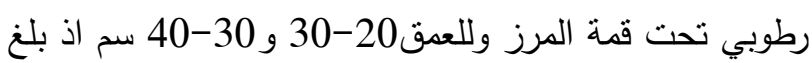

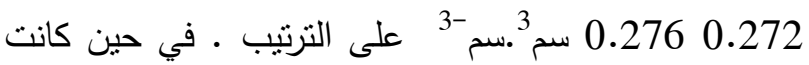

عند تطبيق ري الاحواض 70\% اختلف التوزيع الرطوبي عن

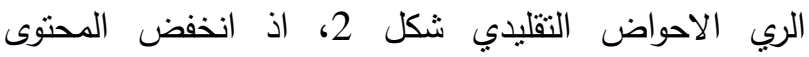
الرطوبي للطبقة السطحية بعد الريه قياسا الى الري الاحواض

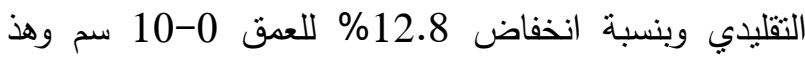
يعود الى انخفاض عمق ماء الري. كما يلاحظ من الثكل ان

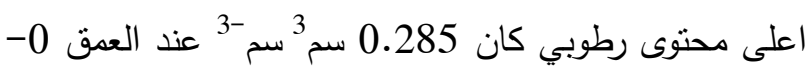
10 سم وانخفض المحتوى تدريجيا مع العمق. وفي الوقت

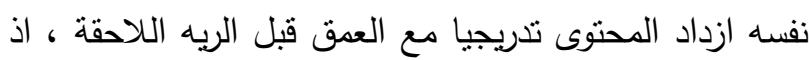

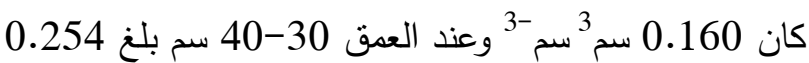
سم3 سم -3 وهي قيمة مقاربة للمحتوى بعد الري بـ24 ساعة.

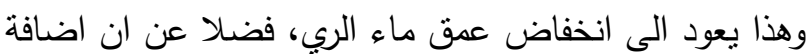

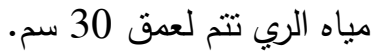
volumetric soil water content $\mathrm{cm}^{3} \mathrm{~cm}^{-3}$

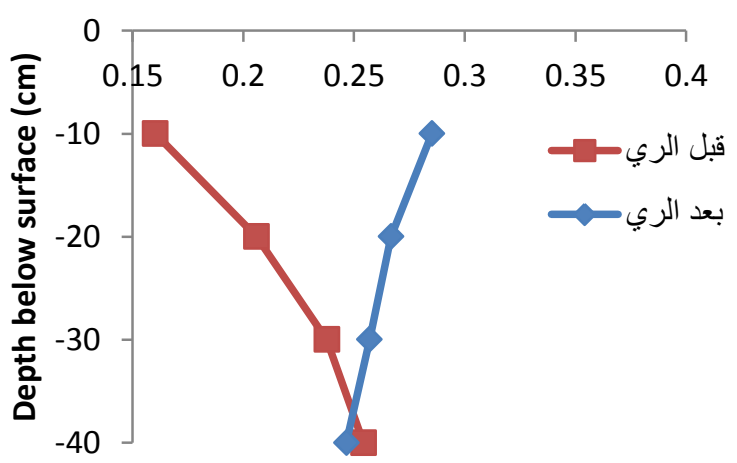

شكل 2. التوزيع الرطوبي لمقد التربة لمعاملة الري الاحواض 70\% بعد الري وقبل الرية اللاحقة.

يبين شكل 3 التوزيع الرطوبي الحجمي لمعاملة المروز التقليدي بعد عملية الري ب24 ساعة، اذ بلغ 0.348

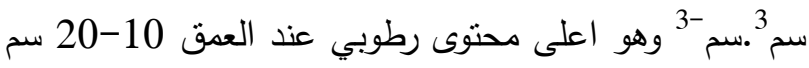
عن قمة المرز، وفي الوقت ذاته انخفض المحتوى الرطوبي عند سطح التربة وبجانب خطوط الزراعة نتيجة سحب الماء

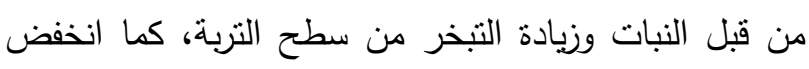

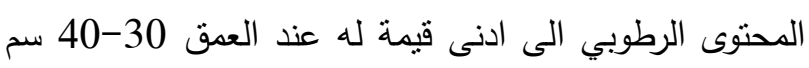

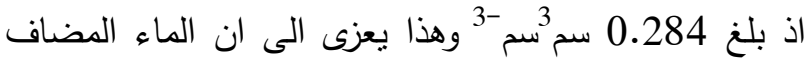
هو لحد العمق 30 سم بحسب معادلة 1. وعدم وصول الماء الى الاعماق تحت سطحية، اذ ان الحراثة هي للعمق 0ـ

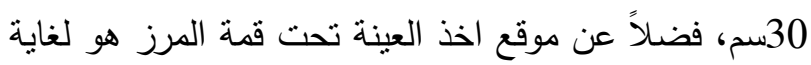
40 سم من سطح التربة، وعند رسم الخطوط الكنتورية فأن برنامج Surfer 10 قدر محتوى رطوبي للعمق 40-50 سم 
بالقياس الى الري التقليدي. اما معاملات ري المروز الضحلة وري الاحواض 70\% فقد بلغ عمق الماء 636 و 618 مم 63

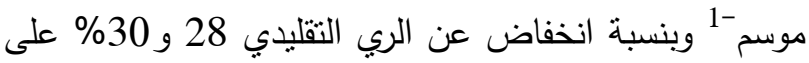
الترتيب. يعزى انخفاض عمق ماء الري المستعمل في الري

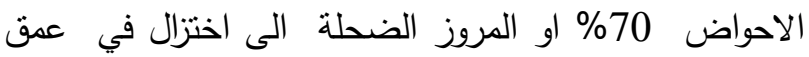

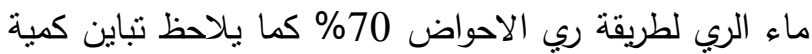

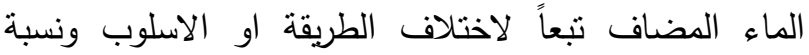
الاختزال في مساحة الترطيب. ويتضح ان تطبيق ري المروز التقليدي والمروز الضحلة وري الاحواض 70\% قد فـ وفرت كمية ماء ري خلال موسم نمو الذرة الصفراء بلغت 2920

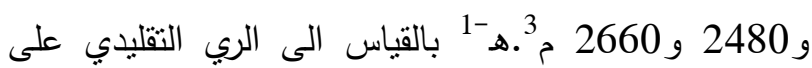
الترتيب. ولحساب المساحة التي بمكن استثمارها من توفير المباه يمكن تطبيق معادلة [3]. يتضح ان نطبيق طريقة ري

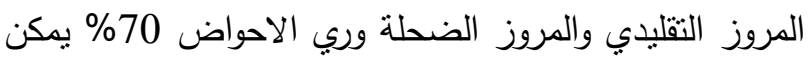
التوسع في الزراعة الافقية للمورد المائي نفسه بمساحه مقدارها 0.49 و 0.39 و 0.43 هوبع فئار على الترتيب. جدول 2. تأثير معاملات الري المختلفة في عمث المثاء المباء المضاف وكمية الماء الموفز ومساحة الارض المائ التي يمكن استثمارها

\begin{tabular}{|c|c|c|c|c|c|}
\hline الاضاضية & الموفرة المبة & 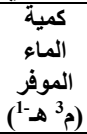 & كمية المـاء & عمث المضاء & التجربة \\
\hline 0 & 0 & 0 & 8840 & 884 & ري احقليدي \\
\hline 0.43 & 0.43 & 2660 & 6180 & 618 & $\begin{array}{c}\text { ري احواض\% } \\
\text { \% }\end{array}$ \\
\hline 0.49 & 0.49 & 2920 & 5920 & 592 & ري مروز \\
\hline 0.39 & 0.39 & 2480 & 6360 & 636 & ري مروز \\
\hline
\end{tabular}

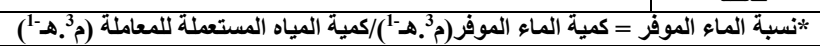
يبين شكل 7 ناثير معاملات الري المختلفة في حاصل حبوب المباء

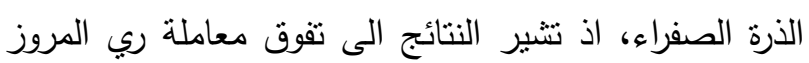

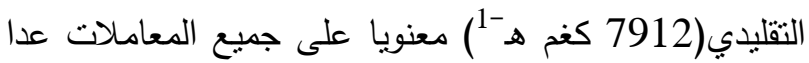
بمعاملة ري الاحواض التقليدي (6531 كغ هـ (-12)، والتي اعطت زيادة بحاصل نسبي مقدارة 121\%. في حين الخفض الحاصل النسبي لمعاملة ري الاحواض 70\%

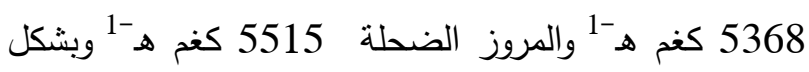
غير معنوي اذ تراوح بين 82 و 844\% عن الري التقلبدي .

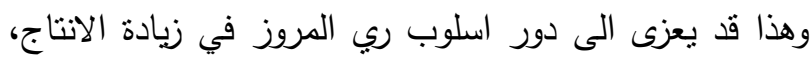

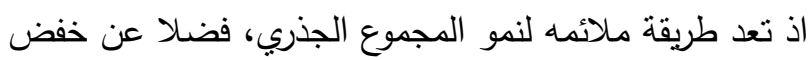
ملوحة التربة وذلك من خلال حركة الاملاح باتجاه قمة المروز • يبين شكل 8 تاثير طرائق الري في كفاءة استعمال
اقل قيم المحتوى الرطوبي هو عند سطح المرز (المحيط

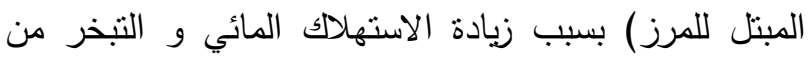
سطح التربة شكل 6. من خلال نتائج التوزيع الرطوبي الحجمي لمعاملات الري المختلفة يتضح ان معاملة المروز الضحلة اعطت اقل انخفاض في المحتوى الرطوبي مقارنة بمعاملة ري الاحواض التقليدي اذ بلغ الانخفاض 14.7 و18.3\% للعمق 0-10سم و 10-20 سم على الترتيب. في حين اعطت معاملة ري الاحواض 70\% اعلى انخفاض في

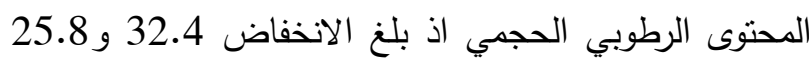

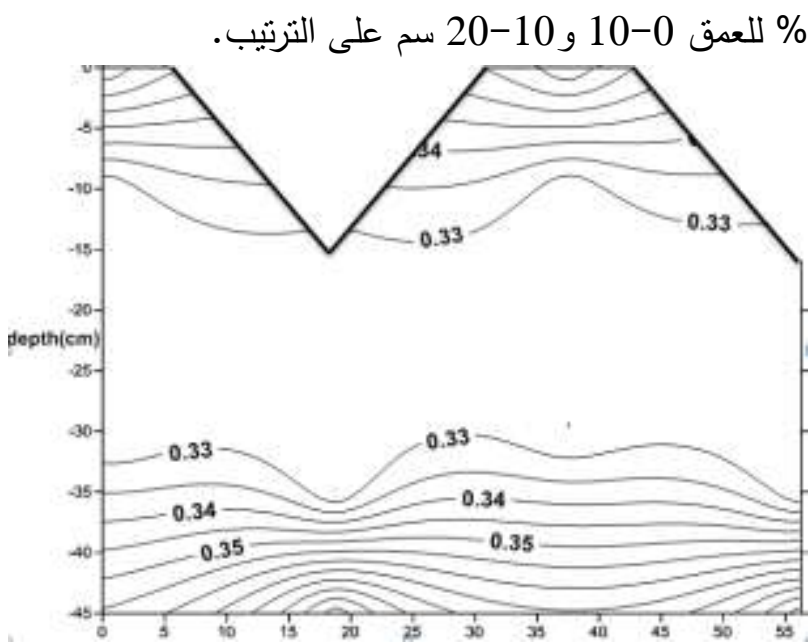

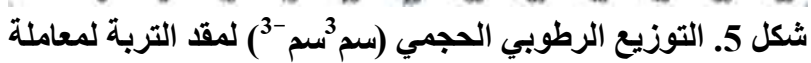
الري المروز الضحلة مع العمق بعد الري.

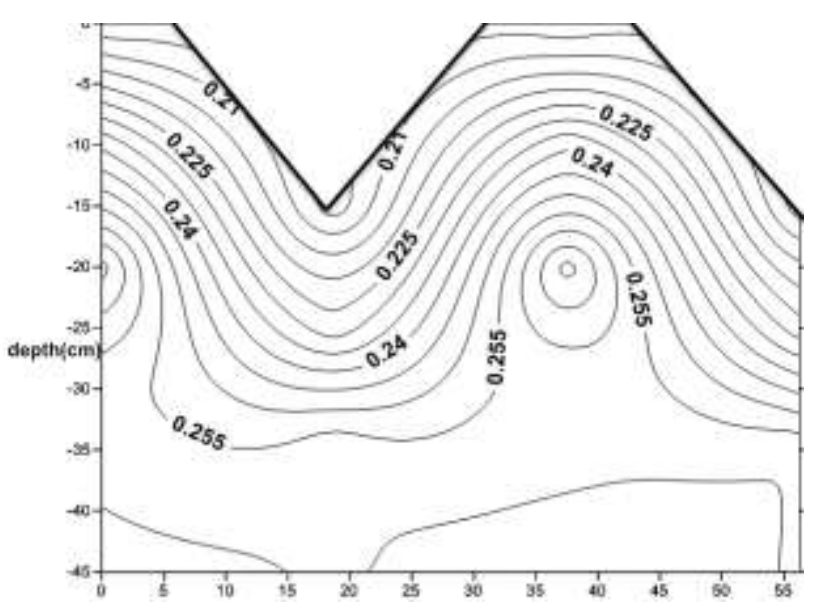

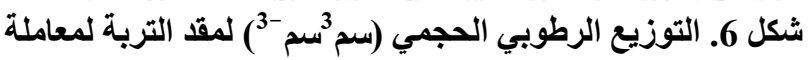
الري المروز الضحلة مع العمق قبل الريه اللاحقة.

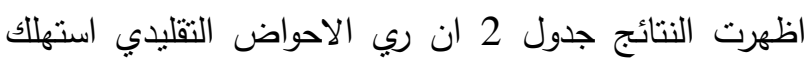

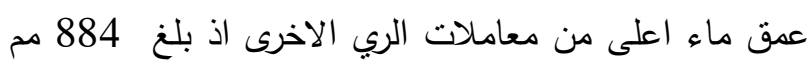

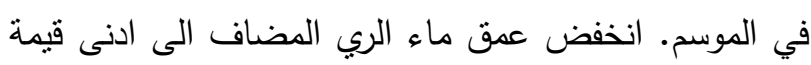

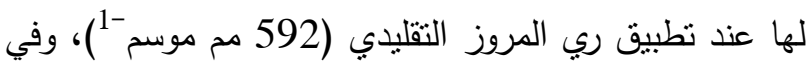
الوقت ذاته بلغت نسبة الانخفاض في عمق الري 33 


\section{REFERENCES}

1.AL-Bayati, A.H. 2006. Effect of alternating irrigation with different salinity water on the growth and yield of some corn genotypes( $\mathrm{Zea}$ mays L.) AL-Taqani Journal. 19(3):1-15.

2.Ali, N.S., A.S.Atee and T.K. Masood. 2016. Effect of nitrogen application and amount of water on yield of intercropped Maize -Mung bean and water productivity. Journal of Agricultural Research and Innovative Technologies. 1(1):1-16.

3.Ati, A.S., K. Makey and T.K. Masood. 2016. Effect of irrigation system basin and furrow in saline distributions patterns and productivity corn (Zea mays L.) Journal of Agriculture and Veterinary Science. 9(5):31-38.

4.Allen, R.G., L.S. Pereira, D. Raes and M. Smith. 1998. Crop Evapotranspiration. FAO Irrigation and Drainage. Paper 65, Rome. 300pp.

5.Black, C.A. 1965. Methods of Soil Analysis. Part (1). Physical and Mineralogical Soil Properties. Am. Soc. Agronomy. Inc. Publisher, Madison, Wisconsin, USA

6.Boelee E (ed) 2011. Ecosystems for water and food security. Nairobi: United Nations Environment Program; Colombo: International Water Management Institute.

7.Hamdy, A. and R. Ragab. 2003. Sustainable Use non - Conventional Water Resources in Agriculture. In. Ragab Ragab (ed). Proceedings of an International Workshop Cairo, Egypt, December 8-10,2003.

8.Kang, S., P. Shi, Y. Pan. Z. Liang, X.T. Hu and J. Zhang. 2000. Soil water distribution, uniformity and water-use efficiency under alternate furrow irrigation in arid areas. Irrig. Sci. 19: 181-190.

9.Kang, S., Z. Liang, Y. Pan, P. Shi and J. Zhang. 2000. Alternate furrow irrigation for maize production in an arid area. Agri. Water Manag. 45: 267-274.

10.Kirda, C. 2002. Deficit Irrigation Scheduling Based on Plant Growth Stages Showing Water Stress Tolerance. Deficit Irrigation Practices, FAO. 102pp.

11.Kovda, V.A., C. Vanden Berg and R.M. Hangun. 1973. Irrigation, Drainage and Salinity. FAO. UNECO. London

12.Masood, T. K. and N. T. Mahdi. 2013. The role of alternate partial irrigation and organic matter on water consumptive use and yield of
المياه اذ بلغت 7.39 و 8.69 و13.36 و 8.67 كغ هـ-1-1.1

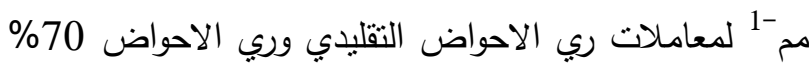

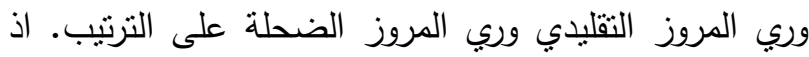
تثنير النتائج تقوق معاملة ري المروز التقليدي معنويا بنسبة زيادة 80\% بالقياس الى ري الاحواض التقليدي، وفي الوقت نفسه اعطت معاملة ري الاحواض 70\% بهادة والمروز الضحلة زيادة غير معنويه تراوحت بين 17.6 و 17.3 \% بالقياس الاسط الى الري الاحواض التقليدي. تعزى زيادة كفاءة استعمال المياه الى دور طريقة ري المروز التقليدية في زيادة الانتاج، فضلا لناديل

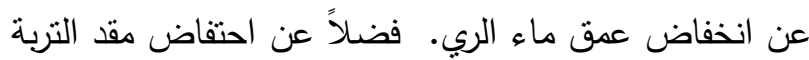
بمحتوى الرطوبي جيد ولاسيما المروز الضحلة ويعد انخفاض مناض كفاءة استعمال الماء لمعاملة الري التقليدي بسبب زيادة كمية مياه الري المضافة، والتي ادت الى زيادة غسل المغذيات اسفل لميل المنطقة الجذرية. بينت نتائج البحث اشارات واضحة حول تطبيق ري المروز التقليدي والمروز الضحلة ودورها في رفع انتاجية المياه والذرة الصفراء.

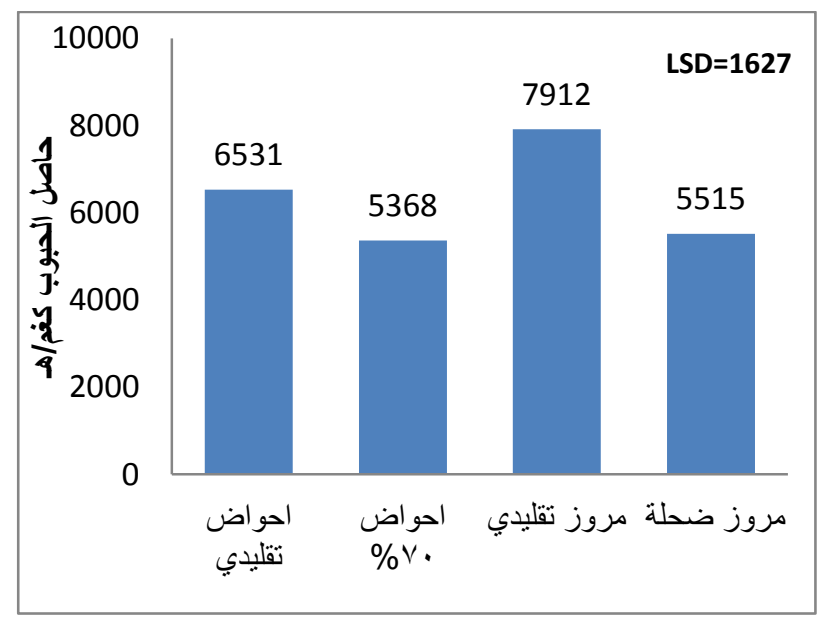

شكل 7. حاصل الحبوب كفم هـ-1.64 لمعاملات الري المختلفة

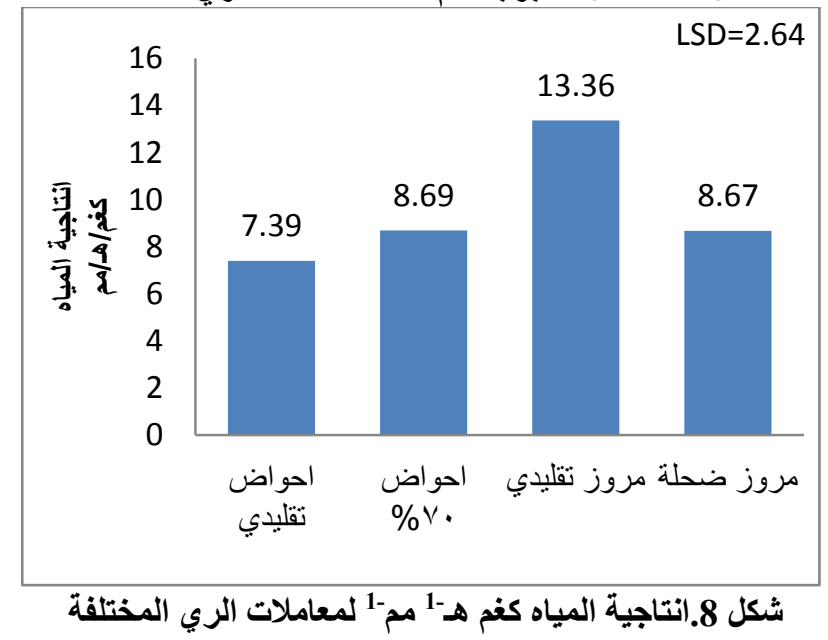


sunflower (Helianthus annuus L.). . Irqi J.Soil.Sci. 13(1):51-59.

13.Masood, T. K. and N. T. Mahdi. 2015. The impact of partial irrigation during sunflower phonological stages and crop factor. Egy. J. App. Sci. 30(5):198-213.

14.Masood, T.K. 2015. Irrigation methods and anti-transpiration as related to wheat and water productivity. The Iraqi J. Agric. Sci. 46(6): 1016-1022.
15.Page, A. L.; R. H. Miller, and D. R. Kenney. 1982. Methods of Soil Analysis Part $2,2^{\text {nd }}$ edition Chemical Properties. Agronomy No. 9. Am. Soc. Agron. Madison, Wiscosin. 16.Rafiee, M. and G.Shakarami. 2010. Water use efficiency of corn as affected by every other furrow irrigation and planting density. World App. Sci. J. 11 (7): 826-829. 17.Tignino, M. 2010. Water, international peace, and security. international review of the red cross.92(879):647-674 